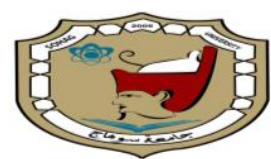

Sohag University
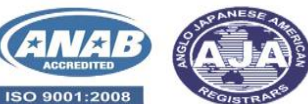

Sohag Medical Journal

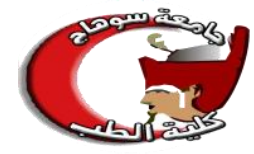

Faculty of Medicine

\title{
Clinico-pathological patterns of Childhood idiopathic steroid-resistant nephrotic syndrome: a retrospective single-center experience
}

\author{
Ghada Ashry B. Abd-Elrehim
}

Pediatric department Sohag Faculty of medicine Sohag University

\begin{abstract}
Introduction and aim of work: Focal segmental glomerulosclerosis is the commonest underlying histopathological diagnosis in idiopathic steroid-resistant nephrotic syndrome in children. Many immunosuppressive therapies are used in its treatment. There is a 50\% risk of progression to end-stage renal disease within five years if there is no complete or even partial remission with immunomodulatory therapies. This work aimed to study the various clinical, histopathological and therapeutic aspects of idiopathic steroid-resistant nephrotic syndrome in our locality.

Patients and Methods: This retrospective study was conducted on children aged 1 15 years with idiopathic steroid-resistant nephrotic syndrome, followed in our Pediatric Nephrology Clinic in Sohag University Hospital, between January 2002 and January 2017. Patients' demographic features and disease's clinical course, histopathological patterns, response to various medications, and long-term outcomes were evaluated.

Results: There were 28 patients with initial and 5 with late steroid resistance. The mean age at disease onset was $3.98 \pm 3.14$ years. The male/female ratio was 2.5/1. Renal biopsy was performed in 26 patients. Minimal change disease was present in 5 patients, mesangioproliferative glomerulonephritis in 6 patients, and focal segmental glomerulosclerosis in 15 patients. Fifteen patients received cyclophosphamide, 26 received cyclosporine, 8 used mycophenolate mofetil, and 4 received combined immunosuppressive therapies. Four patients developed end-stage kidney disease. There were five deaths by the end of the study.

Conclusion: In our study, focal segmental glomerulosclerosis is the most common histopathology in idiopathic steroid-resistant nephrotic syndrome and cyclosporine is the most effective second-line therapy in those patients
\end{abstract}

Keywords: Steroid resistant, focal segmental glomerulosclerosis, cyclosporine, end-stage renal disease.

\section{Introduction}

Idiopathic nephrotic syndrome is one of the most common chronic renal diseases in childhood ${ }^{(\mathbf{1})}$. It is characterized by the presence of primary glomerular disease without detectable causative disease or drug (2). Idiopathic nephrotic children are divided according to their steroid response into a steroidsensitive group (up to $80 \%$ ), and a ste- roid-resistant group. Steroid-sensitive nephrotic children have a good disease outcome, but a risk of relapses. Steroid resistant group has a higher risk of developing chronic kidney disease (CKD) ${ }^{(3)}$. The most frequent underlying histopathology in idiopathic nephrotic syndrome is minimal change disease (MCD) ${ }^{(4)}$. Response of idiopathic 
nephrotic syndrome to steroid treatment and hence the disease outcome is affected by the associated histologic lesion ${ }^{(5)}$. Focal segmental glomerulusclerosis (FSGS) is the most common histological diagnosis in idiopathic steroid-resistant nephrotic syndrome (ISRNS) ${ }^{(6 a n d 7)}$. Many

immunosuppressive therapies are used in the treatment of steroid-resistant nephrotic children, including cyclosporine, cyclophosphamide, mycophenolate mofetil, and rituximab ${ }^{(\mathbf{8})}$. There is a $50 \%$ risk of progression to end-stage renal disease (ESRD) within five years if the steroid-resistant nephrotic patients show no complete or even partial remission with immunomodulatory therapies. Many complications are associated with persistent nephrotic syndrome including poor life quality, hypertension, serious infections, and thromboembolic events. Shortened life expectancy will accompany children who reach ESRD relative to their peers ${ }^{(9)}$. Scanty studies were done about ISRNS patients in our locality in Sohag in spite of the presence of many other types of research inside and outside Egypt focusing on this group of nephrotic patients. The aim of this study is to show our specific experience in the management of those patients and comparing our results with various results inside and outside Egypt.

\section{Patients and Methods}

This was a retrospective study. It was performed on children aged $1-15$ years who have ISRNS. The patients were followed in our Pediatric Nephrology Clinic in Sohag University Hospital, Egypt between January 2002 and January 2017.

Diagnosis of idiopathic nephrotic syndrome depended on the presence of (proteinuria $>40 \mathrm{mg} / \mathrm{h} / \mathrm{m} 2$ or $>50 \mathrm{mg} /-$ $\mathrm{kg} /$ day or protein/creatinine ratio $>2$ $\mathrm{g} / \mathrm{g}$ and hypoalbuminemia $<25 \mathrm{~g} / \mathrm{l}$ with or without edema in the absence of systemic or extrarenal disorders(10and11).

The following definitions were considered for the classification of steroid response patterns ${ }^{(\mathbf{1 0}, \mathbf{1 2})}$.

- Complete remission: proteinuria 0trace on Albustix, $<4 \mathrm{mg} / \mathrm{h} / \mathrm{m}^{2}$, or protein/creatinine ratio in urine $<0.2$ $\mathrm{mg} / \mathrm{mg}$ for 3 consecutive days.

- Partial remission: Reduction of proteinuria by $50 \%$ or greater from the initial value and absolute protein/creatinine ratio in urine between $0.2-$ $2 \mathrm{mg} / \mathrm{mg}$ (20-200 mg/mmol).

- Steroid responsive (steroid sensitive): Complete remission achieved with steroid therapy.

- Steroid resistant or initial non-responder: Failure to achieve remission following 8 weeks of steroid therapy (prednisone $2 \mathrm{mg} / \mathrm{kg} / \mathrm{d}$ or $60 \mathrm{mg} /$ $\mathrm{m} 2 / \mathrm{d}$ for 4 weeks followed by $1.5 \mathrm{~m}$ $\mathrm{g} / \mathrm{kg}$ or $40 \mathrm{mg} / \mathrm{m} 2$ per dose alternate-day for 4 weeks ${ }^{(13)}$. Relapse: Proteinuria $>40 \mathrm{mg} / \mathrm{h} / \mathrm{m} 2,>50 \mathrm{mg}$ $/ \mathrm{kg} /$ day, urine protein/creatinine ratio $\geq 2$ or Albustix +++ for 3 consecutive days after having been in remission.

Patients' demographic features, clinical course, the histopathological patterns for those who underwent renal biopsy, response to various medications, and long-term outcome of the disease were evaluated. Data were collected by the author from patients' medical files.

Inclusion criteria included: 1) Age at disease onset between 1 and 15 years; 2) Having idiopathic steroid-resistant nephrotic syndrome.

Exclusion criteria included: 1) Secondary nephrotic syndrome (caused by another disease). 2)Lack of regular follow-up.

\section{Statistical analysis:}

Statistical package for the social sciences (SPSS) version 16 was used for data analysis. Quantitative variables 
were presented as mean \pm standard deviation. Frequency and percentage were used for qualitative variables.

\section{Ethical consideration}

The Medical Research Ethics Committee of Sohag University approval was obtained before the start of the study without the need for informed written consent from patients' caregivers as the study was retrospective with data collection from patients' medical files provided that all patients' data were treated according to the ethical guidelines with complete respect to patient's privacy and anonymousness.

\section{Results:}

Among 280 idiopathic nephrotic patients, there were 28 patients with initial steroid resistance and 5 patients with late steroid resistance after an initial steroid response representing $12 \%$ of total followed nephrotic patients. The mean age at disease onset in ISRNS was $3.98 \pm 3.14$ years. There were $20(71 \%)$ males and $8(29 \%)$ females, with a male: female ratio was 2.5:1. The mean follow-up duration was $3.7 \pm 2.98$. Initial hematuria and hypertension were present in $17(60.7 \%)$ patients. Out of a total of 33 steroid-resistant patients; renal biopsy was done in 26 patients. The histopathological patterns were MCD in5(19\%) patients, Mesangioproliferative glomerulonephritis (MesPGN) in 6 (23\%) patients, and FSGS in 15 (58\%) patients

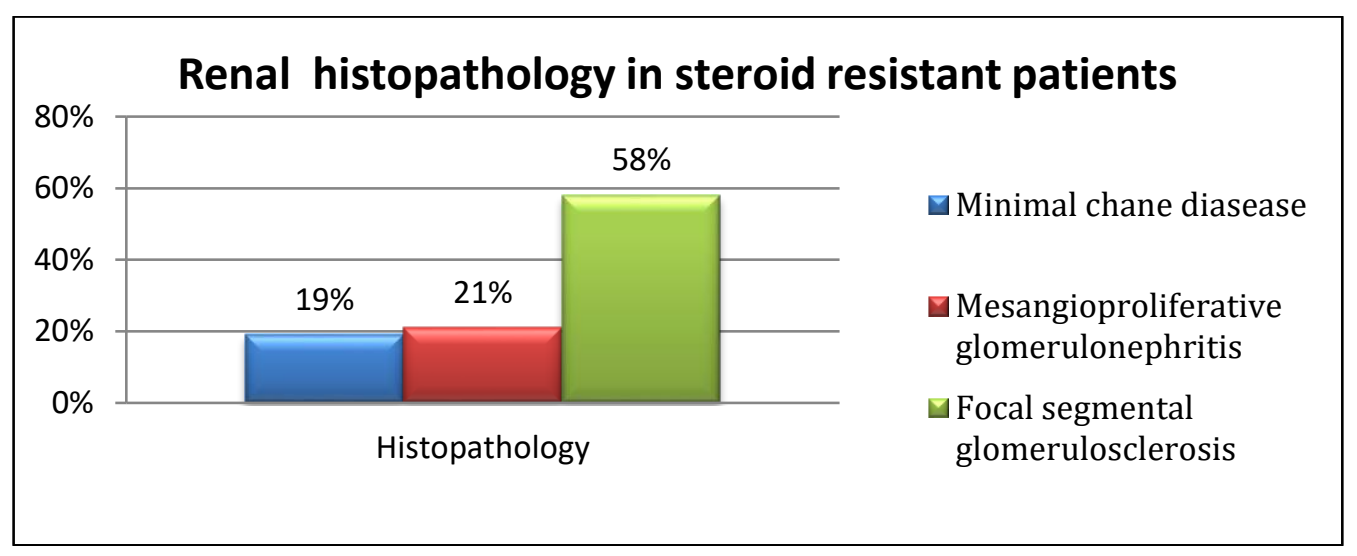

Figure (1): Histopathologic subtypes of biopsied patients with idiopathic steroid-resistant nephrotic syndrome

Out of 33 steroid-resistant patients, 15 (45.5\%) patients received cyclophosphamide, $26(78.8 \%)$ patients received cyclosporine, 8 (24.2\%) patients received mycophenolate mofetil, 4 $(12.1 \%)$ patients received combined immunosuppressive therapies (steroid plus cyclosporine plus mycophenolate mofetil), one (3\%) patient received Mendoza protocol with cyclophosphamide and one (3\%) patient with advanced FSGS used steroid alone and briefly progressed to end-stage renal disease before use of any immune-suppressive therapies. Response of total steroid-resistant patients (initial and late) to alternative therapies concerning their histopathological spectrum is shown in table ${ }^{(1)}$.

Persistent proteinuria developed in 20 $(60 \%)$ patients, (17 patients with no remission and 3 patients with partial remission). The histopathological spectrum of patients with persistent proteinuria showed that: FSGS was present in $13(65 \%)$ patients; MCD in $5(25 \%)$ patients; MesPGN in $1(5 \%)$ patients and in one patient $(5 \%)$ renal biopsy was not done. 
SOHAG MEDICAL JOURNAL

Vol. 25 No. 3 July 2021
Clinico-pathological patterns of Childhood idiopathic Ghada Ashry

Table (1): Response of total steroid-resistant patients (initial and late) to alternative therapies concerning their histopathological spectrum

\begin{tabular}{|c|c|c|c|c|}
\hline \multirow[b]{2}{*}{ Alternative therapies } & \multicolumn{3}{|c|}{ Types of response } & \multirow[b]{2}{*}{ Total } \\
\hline & $\begin{array}{l}\text { Complete } \\
\text { remission }\end{array}$ & $\begin{array}{l}\text { Partial } \\
\text { remission }\end{array}$ & No remission & \\
\hline Cyclophosphamide & $\mathbf{3}(9.1 \%)$ & $\mathbf{0}$ & $\mathbf{1 2}(36.4 \%)$ & $15(45.5 \%)$ \\
\hline MCD & 0 & 0 & $1(100 \%)$ & 1 \\
\hline FSGS & 0 & 0 & $9(100 \%)$ & 9 \\
\hline MesPGN & $2(66.7 \%)$ & 0 & $1(33.3 \%)$ & 3 \\
\hline No biopsy & $1(50 \%)$ & 0 & $1(50 \%)$ & 2 \\
\hline Cyclosporine & $9(27.3 \%)$ & $3(9.1 \%)$ & $14(42.4 \%)$ & $\mathbf{2 6}(78.8 \%)$ \\
\hline MCD & $1(20 \%)$ & $1(20 \%)$ & $3(60 \%)$ & 5 \\
\hline FSGS & $5(29.4 \%)$ & $2(11.8 \%)$ & $10(58.8 \%)$ & 17 \\
\hline MesPGN & $3(75 \%)$ & 0 & $1(25 \%)$ & 4 \\
\hline Mycophenolate mofetil & $\mathbf{0}$ & $\mathbf{0}$ & $8(24.2 \%)$ & $8(24.2 \%)$ \\
\hline$M C D$ & 0 & 0 & $2(100 \%)$ & 2 \\
\hline FSGS & 0 & 0 & $4(100 \%)$ & 4 \\
\hline MesPGN & 0 & 0 & $2(100 \%)$ & 2 \\
\hline Combined therapy & $\mathbf{0}$ & $\mathbf{0}$ & $4(12.1 \%)$ & $4(12.1 \%)$ \\
\hline MCD & 0 & 0 & $2(100 \%$ & 2 \\
\hline FSGS & 0 & 0 & $2(100 \%)$ & 2 \\
\hline Mendoza protocol with & $1(3 \%)$ & 0 & 0 & $1(3 \%)$ \\
\hline FSGS & $1(100 \%)$ & 0 & 0 & 1 \\
\hline Steroid only & $\mathbf{0}$ & $\mathbf{0}$ & $1(3 \%)$ & $1(3 \%)$ \\
\hline FSGS & 0 & 0 & $1(100 \%)$ & 1 \\
\hline Total & $13(39.4 \%)$ & $3(9.1 \%)$ & $\mathbf{1 7}(51.5 \%)$ & $33(100 \%)$ \\
\hline
\end{tabular}

MCD, minimal change disease; FSGS, focal segmental glomerulosclerosis; MesPGN, mesangial-proliferative glomerulonephritis

Within a total of 33 studied patients, end-stage renal disease (ESRD) had occurred in $4(12 \%)$ patients; all of them were with FSGS, 3 of them were steroid and cyclosporine resistant, one of them progressed to ESRD after steroid failure before the introduction of cyclosporine, one of them received $\mathrm{m}$ ycophenolate mofetil after the failure of cyclosporine but without benefit.

There were 5 (15\%) deaths out of a total 33 steroid-resistant studied patients; all of them failed to achieve remission by the various treatment modalities; FSGS was present in $3(60 \%)$ patients and MCD was present in the other 2 $(40 \%)$ patients. The cause of death was ESRD in $3(60 \%)$ patients; all of them were with FSGS and sepsis in $2(40 \%)$ patients; both had MCD. Outcomes of the total included patients by the end of the study are shown in table (2).

Table (2): Outcome of idiopathic steroid-resistant nephrotic syndrome

\begin{tabular}{|l|l|}
\hline Outcome & Number and percentage of patients \\
\hline Persistent proteinuria & $\mathbf{2 0}(60 \%)$ \\
MCD & $5(25 \%)$ \\
FSGS & $13(65 \%)$ \\
MesPGN & $1(5 \%)$ \\
No biopsy & $1(5 \%)$ \\
\hline ESRD & $\mathbf{4}(12 \%)$ \\
FSGS & $4(100 \%)$ \\
\hline Deaths & $\mathbf{5}(15 \%)$ \\
MCD & $2(40 \%)$ \\
FSGS & $3(60 \%)$ \\
\hline
\end{tabular}

MCD, minimal change disease; FSGS, focal segmental glomerulosclerosis; MesPGN, mesangio-proliferative glomerulonephritis 


\section{Discussion}

In our study, $12 \%$ of the followed idiopathic nephrotic syndrome patients were steroid-resistant with a mean age at disease onset of $3.98 \pm 3.14$ years. Male predominance was found with a 2.5:1male: female ratio. The mean follow-up duration was $3.7 \pm 2.98$ which is reasonable to evaluate the disease outcome. Out of a total of 33 steroid-resi- stant patients; renal biopsy was done in 26 patients. The histopathological examination revealed that FSGS was the commonest underlying pattern present in $15(58 \%)$ patients, followed by MesPGN in $6(23 \%)$ patients, and lastly MCDin $5(19 \%)$ patients. Similar and different results were found in the various studies as shown in table (3).

Table (3): Histopathological spectrum of idiopathic steroid-resistant nephrotic syndrome in the various studies

\begin{tabular}{|c|c|c|c|c|c|c|}
\hline \multirow[b]{2}{*}{ Studies } & \multicolumn{5}{|c|}{ Histopathological patterns } & \multirow[b]{2}{*}{ Others } \\
\hline & FSGS & MesPGN & MCD & MPGN & MN & \\
\hline $\begin{array}{l}\text { Our study } \\
\text { (Upper Egypt) }\end{array}$ & $58 \%$ & $23 \%$ & $19 \%$ & & & \\
\hline $\begin{array}{l}\text { Bakr et al, } 2014{ }^{(14)} \\
\text { (Lower Egypt) }\end{array}$ & $19 \%$ & $26 \%$ & $49 \%$ & & & $6 \%$ \\
\hline $\begin{array}{l}\text { Seif et al, 2013 } \\
\text { (Lower Egypt) }\end{array}$ & $30 \%$ & $2 \%$ & $24 \%$ & $8 \%$ & $9 \%$ & $27 \%$ \\
\hline $\begin{array}{l}\text { Alharthi et al, 2016 } \\
\text { (Saudia Arabia) }\end{array}$ & $62 \%$ & $5 \%$ & $14 \%$ & $14 \%$ & $5 \%$ & \\
\hline $\begin{array}{l}\text { Shah SSet al, 2015 } \\
\text { (Pakistan) }\end{array}$ & $10 \%$ & $82 \%$ & $5 \%$ & & & $3 \%$ \\
\hline $\begin{array}{l}\text { Pradhan SK et al, } \mathbf{2 0 1 3}^{(18)} \\
\text { (India) }\end{array}$ & $30 \%$ & $0 \%$ & $45 \%$ & $2.5 \%$ & $5 \%$ & $17.5 \%$ \\
\hline $\begin{array}{l}\text { Inaba A et al, 2016 } \\
\text { (Japan) }\end{array}$ & $32 \%$ & $11 \%$ & $57 \%$ & & & \\
\hline $\begin{array}{l}\text { Banaszak B and Banaszak P, 2012 } \\
\text { (Boland) }\end{array}$ & $22 \%$ & $56 \%$ & $11 \%$ & $11 \%$ & & \\
\hline $\begin{array}{l}\text { Zagury A et al, 2013 } \\
\text { (Brazil) }\end{array}$ & $54 \%$ & $7 \%$ & $39 \%$ & & & \\
\hline $\begin{array}{l}\text { MCD, } \\
\text { segmental } \quad \text { glomerulosclerosis; MesP } \\
\text { membranoproliferative glomerulonephri }\end{array}$ & $\begin{array}{l}\text { ange } \\
\mathbf{N}, \text { me } \\
\text { MN, } 1\end{array}$ & di & se; & glomer & $\begin{array}{l}\text { GS, } \\
\text { oneph }\end{array}$ & ; \\
\hline
\end{tabular}

Variability in the frequency of various histopathological categories in steroidresistant nephrotic syndrome in various studies was observed. This can be attributed to ethnic (environmental and genetic factors). Differences in renal biopsy indications also could explain this difference. In addition, initial pathologic examinations may not detect early focal segmental glomerulosclerosis lesions.

Among the 33 steroid-resistant patients (28 with initial and 5 with late resistance), one (3\%) patient received Mendoza protocol with cyclophosphamide an$\mathrm{d}$ achieved complete remission in this study, $3(9.1 \%)$ patients achieved remission with cyclophosphamide. Many studies revealed a low success rate of cyclophosphamide in steroid-resistant patients. In the Tarshish trial comparing cyclophosphamide plus corticosteroids versus corticosteroids alone, there was also no evidence of benefit with the addition of cyclophosphamide (22). In a study in Turkey, no remission was achieved in the steroid-resistant patients who received cyclophosphamide ${ }^{(23)}$. KDIGO (Kidney Disease Improving Global Outcomes) guidelines do not recommend cyclophosphamide in the treatment of steroid-resistant 
nephrotic syndrome ${ }^{(\mathbf{1 2})}$. Since these guidelines cyclophosphamide is no longer used in our steroid-resistant patients. Cyclosporine was used in 26 steroid-resistant patients in this work with complete remission in $34.6 \%$ of cases and partial remission in $11.5 \%$ of cases. In Renda et al study, $41.6 \%$ of patients achieved complete remission with cyclosporine and $16 \%$ achieved partial remission ${ }^{(23)}$. In Japan, 44\% of steroid-resistant patients achieved complete remission with cyclosporine ${ }^{(24)}$. A slightly higher success rate for cyclosporine was achieved in Brazil as $65 \%$ of cases achieved remission with cyclosporine (21). In our study, there was resistance to mycophenolate mofetil in the eight steroid-resistant patients who received it. Kaddish et al in Cairo treated 6 SRNS patients with MMF where 1 patient showed complete remission, 2 patients showed partial remission and 3 patients were MMF resistant ${ }^{(25)}$. In a study in Saudia Arabia, $40 \%$ of steroid-resistant patients who received mycophenolate mofetil achieved complete remission (26). In Turkey, there was a $66 \%$ resistance rate to mycophenolate mofetil in steroid-resistant patients ${ }^{(23)}$. Up to $60 \%$, the complete remission rate was achieved with mycophenolate mofetil in Colombia(27). No explanation till now is present for the total resistance to mycophenolate mofetil in our patients and further researches are needed.No no response to combined immunosuppressive therapy (Steroid, cyclosporine, and mycophenolate mofetil) in our steroid-resistant patients.

Persistent proteinuria was present in 20 $(60 \%)$ of patients with steroid resistance (initial and late) in our study. Eighty percent of them were with initial steroid resistance and $20 \%$ of them were with late steroid resistance. Focal segmental glomerulosclerosis represented most of these cases (65\%), followed by minimal change disease in
$25 \%$, mesangial-proliferative glomerulonephritis in only $5 \%$ of these cases and 5\% were without renal biopsy. Those patients with persistent proteinria were either resistant to immunosuppressive therapy $(85 \%)$ or partially responders $(15 \%)$. End-stage renal disease developed in $4(12 \%)$ patients in this study, all of them had persistent proteinuria, with resistance to other immunesuppressive therapies. Focal segmental glomerulosclerosis was the only underlying renal histopathology in end-stage renal disease. Near results were encountered in Alharthi et al study, as $16.7 \%$ of steroid-resistant patients had progressed to end-stage renal disease, Roy et al study in Bangladesh as $12.5 \%$ of steroid-resistant patients ended with end-stage renal disease ${ }^{\mathbf{( 1 6} \text {, }}$ 28). respectively. In a large study in Taiwan, end-stage renal disease had occurred in $3.6 \%$ of total idiopathic nephrotic patients (29). Focal segmental glomerulosclerosis as the initial histopathological pattern is found to be a predictive factor of progression to endstage renal disease, particularly in those who could not attain remission $(19,30,31,32$, 33and 34).

In the present study, 4 out of 19 patients with focal segmental glomerulosclerosis $(21.1 \%)$ reached end-stage renal disease before the end of the study, three of them were cyclosporine resistant and one reached end-stage renal disease before the introduction of cyclosporine. This was in agreement with other studies which suggest that cyclosporine resistance and focal segmental glomerulosclerosis are predictors for end-stage renal disease as patients with focal segmental glomerulosclerosis are 9.25 times more likely to develop the end-stage renal disease than patients with minimal change disease, as well as patients with cyclosporine resistance are 4.3 times more likely to develop the end-stage renal disease than cyclosporine-sensitive pa- 
tients ${ }^{(21)}$. One of the most recent studies in the long-term outcome of childhood nephrotic syndrome concludes that the underlying renal histopathology, genetic factors, and ethnicity likely modulate response to treatment and progression of end-stage renal disease $^{(35)}$. There were $5(15 \%)$ deaths out of the total studied patients. All of them were immunosuppressive therapy-resistant. The underlying histopathological patterns were focal segmental glomerulosclerosis in $60 \%$ of patients and minimal change disease in the other $40 \%$ of patients. The causes of death were end-stage renal disease in patients with focal segmental glomerulosclerosis and massive sepsis in patients with minimal change disease.

Some limitations were present in our study including that it was a retrospective, single-center study with a small number of patients who fulfilled the inclusion criteria and completed their follow-up. Also, some patients refused renal biopsy procedures and genetic data about our patients was deficient. In conclusion, in our study focal segmental glomerulosclerosis is the most common histopathological type in idiopathic steroid-resistant nephrotic syndrome and carries the worst prognosis but this is not the same in other studies. Response to alternative immunomodulatory agents improves the outcome of steroid-resistant patients. Cyclosporine is the most effective second-line therapy in steroid-resistant nephrotic syndrome.

\section{References}

1. McCaffrey J, Lennon R, Webb NJ. The non-immunosuppressive management of childhood nephrotic syndrome. Pediatr Nephrol. 2016; 31:1383-1402.

2. Pais P, Avner ED. Nephrotic syndrome. In: Kliegman RM, Stanton BF, Geme JW, Schor NF editors: Nelson Textbook of pediatrics, 20th ed,
Philadelphia, Elsevier Inc, 2016; 527:2521-2527.

3. Chanchlani R, Parekh RS. Ethnic Differences in Childhood Nephrotic Syndrome. Frontiers in Pediatrics. 2016; 4:39.

4. ISKDC (International Study of Kidney Disease in Children). Nephrotic syndrome in children: prediction of histopathology from clinical and laboratory characteristics at the time of diagnosis. A report of the International Study of Kidney Disease in Children. Kidney Int. 1978; 13:159-165.

5. ISKDC (International Study of Kidney Disease in Children). The primary nephrotic syndrome in children: Identification of patients with minimal change nephrotic syndrome from initial response to prednisone. A report of the International Study of Kidney Disease in Children. J Pediatr. 1981; 98(4):561564.

6. Churg J, Habib R, White RH. Pathology of the nephrotic syndrome in children: a report for the international study of kidney disease in children. Lancet. 1970; 760:1299-1302.

7. Saleem MA. New developments in steroid-resistant nephrotic syndrome. Pediatr Nephrol. 2013; 28:699-709.

8. Lombel RM, Gipson DS, Hodson EM (). Treatment of steroid-sensitive nephrotic syndrome: new guidelines from KDIGO. Pediatric nephrology. 2013; 28(3):415-26.

9. Erkan E: Nephrotic syndrome. In: Kliegman RM, Stanton BF, Geme JW, Schor NF, Behrman RE editors: Nelson Textbook of pediatrics, 21st ed, Philadelphia, Elsevier Inc, 2020; 545.1:10806-10835.

10.Niaudet P, Boyer O. Idiopathic nephrotic syndrome in childhood: clinical aspects. In: Avner ED, Harmon WE, Niaudet P, Yoshikawa N editors: Pediatric Nephrology. 6th ed. Germany: Springer-Verlag, 2009; 667702.

11.Pais, Ellis, Avner ED: Nephrotic syndrome. In: Kliegman RM, Stanton BF, Geme JW, Schor NF, Behrman RE, editors: Nelson Textbook of pediatrics 19th ed, Philadelphia, 
Elsevier Saunders, 2011; 521:18011807.

12.KDIGO (Kidney Disease Improving Global Outcomes) Glomerulonephritis Work Group. KDIGO clinical practice guideline for glomerulonephritis. Kidney Int Suppl. 2012; 2:139-274.

13.Gipson DS, Massengill SF, Yao L, Nagaraj S, Smoyer WE, Mahan JD, et al. Management of childhood-onset nephrotic syndrome. Pediatrics. 2009; 124(2):747-757

14.Bakr A, Eid R, Sarhan A, Hammad A, El-Refaey AM, et al. Pathological profile of biopsied Egyptian children with primary nephrotic syndrome: 15year single-center experience $\mathbf{J}$ Nephrol. 2014; 27(4):419-423

15.Seif EI, Eman Ibrahim AS, Elhefnawy NG, Salman MI. Histological patterns of idiopathic steroid-resistant nephrotic syndrome in Egyptian children: A single centre study. J Nephropathology. 2013; 2(1):53-60

16. Alharthi AA. Patterns of Childhood Steroid-Sensitive and Steroid-Resistant Nephrotic Syndrome in Saudi Children: Clinicopathological Study of 87 Cases. Clinical Pediatrics. 2016; 1-7. DOI: 10.1177/0009922816645521

17. Shah SS, Akhtar N, Sunbleen F, Rehman MF, Ahmed T: Histopathological patterns in pediatric idiopathic steroid-resistant nephrotic syndrome. J Ayub Med Coll Abbottabad.2015; 27(3):633-636

18.Pradhan SK, Mutalik PP, Mohanty AK. A pattern of steroid-resistant nephrotic syndrome in children and the role of histopathology: A single-center study. South African Journal. 2013; 7(4):153154

19.Inaba A, Hamasaki Y, Ishikura K, Hamada R, Sakai T, et al. Long-term outcome of idiopathic steroid-resistant nephrotic syndrome in children. Pediatr Nephrol. 2016; 31:425-434

20.Banaszak B and Banaszak P. The increasing incidence of initial steroid resistance in childhood nephrotic syndrome. Pediatr Nephrol. 2012; 27:927-932

21.Zagury A, Oliveira AL, Montalvo JA, Novaes RH, Sa VM, Moraes CA, et al. Steroid-resistant idiopathic nephrotic syndrome in children: long-term follow-up and risk factors for end-stage renal disease. J Bras Nefrol. 2013; 35(3):191-199

22. Tarshish P, Tobin JN, Bernstein J et al. Cyclophosphamide does not benefit patients with focal segmental glomerulosclerosis. A report of the International Study of Kidney Disease in Children. Pediatr Nephrol. 1996; 10:590-593

23.Renda R, Aydoğ Ö, Bülbül M, Çakıcı EK. Children with Steroid-resistant Nephrotic Syndrome: a Single-Center Study. Int J Pediatr. 2016; 4(25):12331242

24.Hibino S, Uemura O, Nagai $T$, Yamakawa S, Iwata N, Ito H, Nakano M, Tanaka K. Three-year outcome of childhood idiopathic nephrotic syndrome under a unified immunosuppressive protocol. Pediatrics International. 2015; 57:8591

25.Kaddish A, Sabry S, Emil E, El-Refaey M. Epidemiology of primary nephrotic syndrome in Egyptian children. $\mathbf{J}$ Nephrol. 2012; 25 (05):732-737

26.Kari JA, Halawani M. Treatment of Steroid Resistant Nephrotic Syndrome in Children. Saudi J Kidney Dis Transpl. 2010; 21(3):484-487

27.Echeverri CV, Valencia GA, Higuita LM, Gayubo AK, Ochoa CL, et al. Immunosuppressive therapy in children with steroid-resistant nephrotic syndrome: a single-center experience. $\mathbf{J}$ Bras Nefrol. 2013; 35(3):200-205

28. Roy RR, Haque SMS, Mamun AA, Muinuddin G, Rahman MH. Steroid resistant nephrotic syndrome in children: Clinical presentation, renal histology, complications, treatment and outcome at Bangabandhu Sheikh Mujib Medical University, Dhaka, Bangladesh. IOSR Journal of Pharmacy. 2014; 4(11):1-7

29.Chang JW, Tsai HL, Yang LY, Chen TJ. Epidemiology and Predictors of End-stage Renal Disease in Taiwanese Children With Idiopathic Nephrotic Syndrome. J Epidemiol. 2012; 22(6):517-522

30. Martinelli R, Okumura AS, Pereira LJ, Rocha H. Primary focal segmental 
glomerulosclerosis in children: prognostic factors. Pediatr Nephrol. 2001; 16:658-661

31.Kirpekar R, Yergin PD, Tune BM, Kim MK, Sibley RK. Clinicopathologic correlates predict the outcome in children with steroid-resistant idiopathic nephrotic syndrome treated with pulse methylprednisolone therapy. Am J Kidney Dis. 2002; 39:1143-1152

32.Gipson DS, Chin H, Presler TP, Jennette C, Ferris ME, et al. Differential risk of remission and ESRD in childhood FSGS. Pediatr Nephrol. 2006; 21:344-349
33. Abrantes MM, Cardoso LS, Lima EM, Silva PJM, et al. Predictive factors of chronic kidney disease in primary focal segmental glomerulosclerosis. Pediatr Nephrol 2006; 21:1003-1012

34.Paik KH, Lee BH, Cho HY, Kang HG, Ha IS, Cheong HI, et al. Primary focal segmental glomerular sclerosis in children: clinical course and prognosis. Pediatr Nephrol. 2007; 22(3):389-395

35. Hjorten R, Anwar Z, Reidy KJ. Longterm Outcomes of Childhood-Onset nephrotic Syndrome. Frontiers in Pediatrics. 2016; 4(53):1-7 